The Astrophysical Journal SuPplement SeriES, 133:255-267, 2001 March

(C) 2001. The American Astronomical Society. All rights reserved. Printed in U.S.A.

\title{
ELECTRON-ION RECOMBINATION RATE COEFFICIENTS AND PHOTOIONIZATION CROSS SECTIONS FOR ASTROPHYSICALLY ABUNDANT ELEMENTS. V. RELATIVISTIC CALCULATIONS FOR Fe XXIV
} AND Fe XXV FOR X-RAY MODELING

\author{
Sultana N. Nahar and Anil K. Pradhan \\ Department of Astronomy, The Ohio State University, Columbus, OH 43210
}

AND

\author{
HoNG LIN ZhaNG \\ Applied Theoretical and Computational Physics Division, MS F663, Los Alamos National Laboratory, Los Alamos, NM 87545 \\ Received 2000 July 21 ; accepted 2000 September 15
}

\begin{abstract}
Photoionization and recombination cross sections and rate coefficients are calculated for Li-like Fe XXIV and He-like Fe XXv using the Breit-Pauli $R$-matrix (BPRM) method. A complete set of total and level-specific parameters is obtained to enable X-ray photoionization and spectral modeling. The ab initio calculations for the unified $(e+$ ion) recombination rate coefficients include both the nonresonant and the resonant recombination (radiative and dielectronic recombination, RR and DR, respectively) for $(e+\mathrm{Fe} \mathrm{XXV}) \rightarrow \mathrm{Fe}$ XXIV and $(e+\mathrm{Fe} \mathrm{XXVI}) \rightarrow \mathrm{Fe}$ XXv. The level-specific rates are computed for all finestructure levels up to $n=10$, enabling accurate computation of recombination-cascade matrices and effective rates for the X-ray lines. The total recombination rate coefficients for both Fe XXIV and $\mathrm{Fe}$ XXV differ considerably from the sum of RR and DR rates currently used to compute ionization fractions in astrophysical models. As the photoionization/recombination calculations are carried out using an identical eigenfunction expansion, the cross sections for both processes are theoretically self-consistent; the overall uncertainty is estimated to be about $10 \%-20 \%$. All data for Fe XXIV and Fe XXV (and also for H-like Fe XXVI, included for completeness) are available electronically.
\end{abstract}

Subject headings: atomic data - atomic processes — line: formation - X-rays: general

\section{INTRODUCTION}

Photoionization and recombination of Li-like and He-like ions is of particular interest in X-ray astronomy (e.g., Bautista, Kallman, \& Pradhan 2000). ${ }^{1}$ X-ray photoionization models in general require these parameters over all ranges of photon energies and temperatures prevalent in high-temperature sources such as active galactic nuclei, supernova remnants, and hot stellar coronae (Canizares et al. $2000 ;{ }^{1}$ Brickhouse \& Drake 2000 ${ }^{1}$ Kaastra \& Mewe 2000). ${ }^{1}$ High precision is increasingly a prime requirement owing to the detailed observational spectroscopy from space observatories, particularly $A S C A, C X O$, and XMMNewton. X-ray emission in the $6.7 \mathrm{keV} \mathrm{K} \alpha$ complex of He-like Fe XXv from the $n=2 \rightarrow 1$ transitions yields valuable spectral diagnostics for temperature, density, ionization balance, and abundances in the plasma source (Gabriel 1972; Mewe \& Schrijver 1978; Pradhan \& Shull 1981; BelyDubau et al. 1982; Pradhan 1985). Dielectronic satellite lines of Fe xxIv formed due to $(e+$ ion) recombination with $\mathrm{Fe} \mathrm{XXV}$ are useful as temperature diagnostics in both laboratory and astrophysical sources. Ionization balance and spectral studies therefore require comprehensive sets of photoionization/recombination cross sections.

For highly charged ions it is important to consider relativistic fine structure explicitly in the theoretical formulation, in addition to the often strong electron correlation effects. The close coupling approximation, employing the

\footnotetext{
${ }^{1}$ http://heasarc.gsfc.nasa.gov/docs/heasarc/atomic/proceed.html. Page numbers have been listed for the three following articles in the Ref list.
}

$R$-matrix method, has been widely employed to compute radiative and collisional parameters, such as under the Iron Project (Hummer et al. 1993). The close coupling calculations for the He- and Li-like ionization states involve eigenfunction expansions for the $\mathrm{H}$ - and He-like target ions, respectively, and it is necessary to include relativistic effects and highly resolved fine structure with radiatively damped resonances for high precision. Therefore, in order to improve the accuracy of available photoionization/ recombination parameters, as well as to provide extensive sets of data needed for astrophysical models, we have recalculated these using relativistic Breit-Pauli $R$-matrix method (hereafter BPRM). The first such calculations were reported for He- and Li-like C V and C IV in the present series (Nahar, Pradhan, \& Zhang 2000), together with a detailed description of the relativistic close coupling calculations for photoionization and recombination cross sections (total and level-specific) and unified $(e+$ ion) recombination rates. The present work is basically similar and extends the treatment to iron ions.

\section{THEORY}

The electron-ion recombination calculations entail close coupling calculations for photoionization and electron-ion scattering. Identical eigenfunction expansion for the target (core) ion is employed for both processes, thus enabling inherently self-consistent photoionization/recombination results in an ab initio manner for a given ion. General details of the theory and close coupling BPRM calculations for photoionization and recombination are described in Nahar et al. (2000) and references therein. We sketch below the basic outline of the theoretical formulation. 
We consider photoionization from, and recombination into, the infinity of levels of the $(e+$ ion $)$ system. These are divided into two groups of bound levels: group A with $v \leq v_{o}$ and all possible fine-structure SLJ symmetries, and group B with $v_{o}<v \leq \infty$, where $v$ is the effective quantum number relative to the target threshold(s). Photoionization and recombination calculations are carried out in detail for all group A levels. The photorecombination cross sections are computed from the photoionization cross sections at a sufficiently large number of energies to delineate the nonresonant background and the autoionizing resonances, thereby representing both radiative and the dielectronic recombination (RR and $\mathrm{DR}$ ) processes. Recombination into group B levels with $v>v_{o}$ is considered as entirely due to DR, neglecting the nonresonant background in the energy region where RR is usually extremely small. The theory by Bell \& Seaton (1985) is applied (Nahar \& Pradhan 1994) to calculate the DR collision strengths. The $v_{o}$ can assume any value consistent with the method but is usually taken to be 10. Background photoionization cross sections of the highRydberg group B levels are computed hydrogenically (referred to as the "high-n top-up"; Nahar 1996), using procedures developed by Storey \& Hummer (1992).

Several atomic effects related to the present calculations are also discussed in Nahar et al. (2000). In particular, it is pointed out that for the $\mathrm{H}$-like and the He-like target ions, with strong dipole-allowed $2 p \rightarrow 1 s$ and $1 s 2 p\left({ }^{1} P_{1}^{o}\right) \rightarrow 1 s^{2}$ $\left({ }^{1} S_{0}\right)$ transitions respectively, autoionizing resonances are radiatively damped to a significant extent, and this is taken into account in the calculation of detailed photoionization cross sections. In a test study on radiation damping, Pradhan \& Zhang (1997) described a numerical fitting procedure to account for the autoionization versus radiative decay of resonances. They also computed the dielectronic satellites of Fe XXIV $(e+\mathrm{Fe}$ XXv) and compared those with experimental data. Zhang, Nahar, \& Pradhan (1999) further reported BPRM calculations for a few individual resonance complexes (KLL, KLM, KLN, KLO, and KLP) and compared with earlier works (discussed later).

\section{COMPUTATIONS}

Computations of $\sigma_{\mathrm{PI}}$ in the relativistic BPRM intermediate-coupling approximations are carried out using the package of codes from the Iron Project (Berrington, Eissner, \& Norrington 1995; Hummer et al. 1993), extended from the Opacity Project (OP) codes (Berrington et al. 1987; Opacity Project Team 1995, 1996). Radiation damping of resonances up to $n=10$ are included through use of the extended codes STGF and STGBF (Zhang et al. 1999; Nahar \& Pradhan 1994). The BPRM calculations are carried out for each total angular momentum symmetry $J \pi$, corresponding to a set of fine-structure target levels $J_{t}$. The target wave functions were obtained from atomic structure calculations using updated version of the code SUPERSTRUCTURE (Eissner, Jones, \& Nussbaumer 1974).

The level-specific recombination cross sections $\sigma_{\mathrm{RC}}(i)$, into level $i$ of the recombined $(e+$ ion) system, are obtained from the partial photoionization cross sections $\sigma_{\mathrm{PI}}(i, g)$ of level $i$ into the ground level of the recombining ion. These detailed (photo)recombination cross sections are calculated in the energy region from threshold up to about $v=v_{o}=$ 10 , where $v$ is the effective quantum number relative to the target level of the recombining ion. Particular care is taken to delineate the resonances up to $v \leq v_{o}$ completely. The electrons in this energy range generally recombine to a large number of final $(e+$ ion $)$ levels. Recombination cross sections are computed for all coupled symmetries and levels and are summed to obtain the total $\sigma_{\mathrm{RC}}$.

In the higher energy region, $v_{o}<v<\infty$, below each threshold target level, where the resonances are narrow and dense and the background is negligible, we compute the detailed and the resonance-averaged DR cross sections. The DR collision strengths in BPRM are obtained using extensions of the $R$-matrix asymptotic region code STGF (Nahar \& Pradhan 1994; Zhang et al. 1999). It is necessary to use extremely fine energy mesh in order to delineate the resonance structures belonging to each $n$-complex.

The level-specific recombination rate coefficients are obtained using a new computer program, BPRRC (Nahar et al. 2000). The level-specific rates are obtained for energies going up to infinity. These rates include both nonresonant and resonant contributions up to energies $z^{2} / v_{o}^{2}$; contributions from all autoionizing resonances up to $v \leq v_{o} \approx 10$ are included.

The program BPRRC sums up the level-specific rates, which is added to the contributions from the resonant high- $n$ DR, from resonances with $v_{o}<v<\infty$, to obtain total recombination rates. As an additional check on the numerical calculations, the total recombination rate coefficients, $\alpha_{R}$, are also calculated from the total recombination collision strength, $\Omega_{\mathrm{RC}}$, obtained from all the photoionization cross sections, and the DR collision strengths. The agreement between the two numerical approaches is within a few percent.

Finally, the background (nonresonant) contribution from the high- $n$ states $(10<n \leq \infty)$ to the total recombination is also included as the "top-up" part and is computed in the hydrogenic approximation (Nahar 1996). This contribution is important at low temperatures but negligible at high temperatures. The rapid rise in $\alpha_{R}$ toward very low temperatures is due to low energy recombination into the infinite number of these high- $n$ states, at electron energies not usually high enough for resonant excitations and DR stabilization.

The program BPRRC is also used to extend the total photoionization cross sections in the high-energy region, beyond the highest target threshold in the close coupling

TABLE 1

Target Terms in the Eigenfunction Expansions of Fe xxv AND Fe XXVI

\begin{tabular}{|c|c|c|c|}
\hline \multicolumn{2}{|c|}{$\mathrm{Fe} x \mathrm{xv}$} & \multicolumn{2}{|c|}{ Fe XXVI } \\
\hline $1 s^{2}\left({ }^{1} S_{0}\right)$ & 0.0 & $1 s\left({ }^{2} S_{1 / 2}\right) \ldots \ldots$ & 0.00 \\
\hline $1 s 2 s\left({ }^{3} S_{1}\right) \ldots \ldots$ & 487.774760 & $2 p\left({ }^{2} P_{1 / 2}^{o}\right) \ldots \ldots$ & 510.9598 \\
\hline $1 s 2 p\left({ }^{3} P_{0}^{o}\right) \ldots \ldots$ & 489.899743 & $2 s\left({ }^{2} S_{1 / 2}\right) \ldots \ldots$ & 511.0012 \\
\hline $1 s 2 p\left({ }^{3} P_{1}^{o}\right) \ldots \ldots$ & 490.071608 & $2 p\left({ }^{2} P_{3 / 2}^{o}\right) \ldots \ldots$ & 512.5190 \\
\hline $1 s 2 s\left({ }^{1} S_{0}\right) \ldots \ldots$ & 490.091292 & $3 p\left({ }^{2} P_{1 / 2}^{o}\right) \ldots \ldots$ & 606.0989 \\
\hline $1 s 2 p\left({ }^{3} P_{2}^{o}\right) \ldots \ldots$ & 491.132414 & $3 s\left({ }^{2} S_{1 / 2}\right) \ldots \ldots$ & 606.1118 \\
\hline $1 s 2 p\left({ }^{1} P_{1}^{o}\right) \ldots \ldots$ & 492.448740 & $3 p\left({ }^{2} P_{3 / 2}^{o}\right) \ldots \ldots$ & 606.5603 \\
\hline $1 s 3 s\left({ }^{3} S_{1}\right) \ldots \ldots$ & 579.251214 & $3 d\left({ }^{2} D_{5 / 2}\right) \ldots \ldots$ & 606.5612 \\
\hline $1 s 3 p\left({ }^{3} P_{0}\right) \ldots \ldots$ & 579.251214 & $3 d\left({ }^{2} D_{3 / 2}\right) \ldots \ldots$ & 606.71180 \\
\hline $1 s 3 s\left({ }^{1} S_{0}\right) \ldots \ldots$ & 579.251214 & & \\
\hline $1 s 3 p\left({ }^{3} P_{1}^{o}\right) \ldots \ldots$ & 579.251214 & & \\
\hline $1 s 3 p\left({ }^{3} P_{2}^{o}\right) \ldots \ldots$ & 579.251214 & & \\
\hline $1 s 3 p\left({ }^{1} P_{1}^{o}\right) \ldots \ldots$ & 579.251214 & & \\
\hline \multicolumn{2}{|c|}{$13-\mathrm{CC}$} & \multicolumn{2}{|c|}{ 9-CC } \\
\hline
\end{tabular}

NOTE. - The target energies are in rydbergs. 

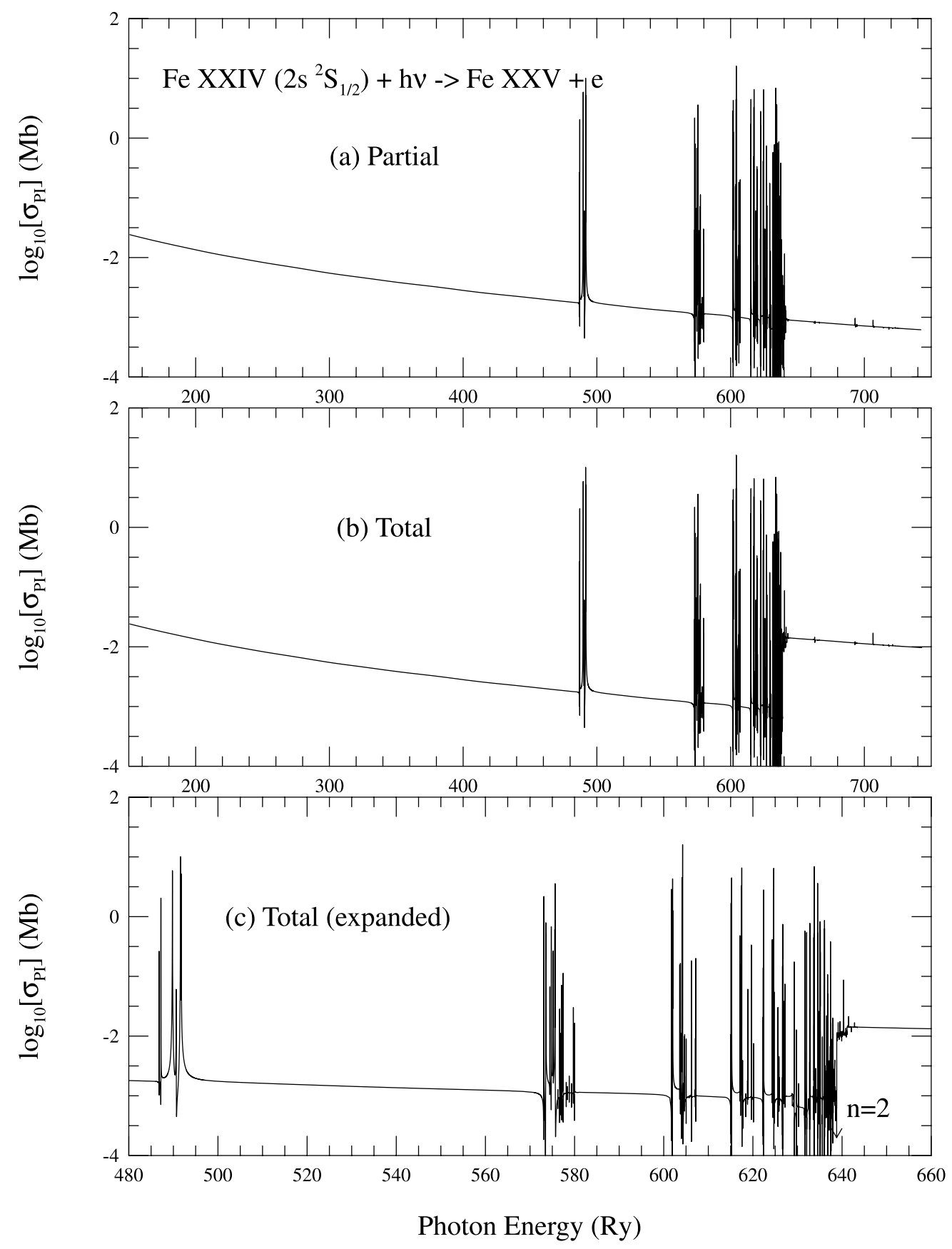

FIG. 1.-Photoionization of the ground state $1 s^{2} 2 s\left({ }^{2} S_{1 / 2}\right)$ of Fe XxIv: (a) partial cross section into the ground level $1 s^{2}\left({ }^{1} S_{0}\right)$ of Fe Xxv ; $(b)$ total cross section; $(c)$ an expanded view of the resonances and inner shell thresholds. The large jump in $(b)$ corresponds to the $\mathrm{K}$-shell ionization edge.

wave function expansion of the ion, by a tail from Kramers fit of $\sigma_{\mathrm{PI}}(E)=\sigma_{\mathrm{PI}}^{o}\left(E^{o} / E\right)^{3}$, where $E^{o}$ is the last tabulated energy above all target thresholds.

Below we describe the calculations individually for the ions under consideration.

\section{1. $e+\mathrm{Fe} \mathrm{XXV} \rightarrow \mathrm{Fe} \mathrm{XXIV}$}

The fine-structure levels of the target ion, $\mathrm{Fe} \mathrm{xxv}$, included in the wave function expansion for Fe XXIV are given in Table 1. The 13 fine-structure levels of Fe Xxv up to $1 s 3 p$ correspond to configurations $1 s^{2}, 1 s 2 s, 1 s 2 p, 1 s 3 s$, and $1 s 3 p$ (correlation configurations include those with the $3 d$ orbital). Although calculated energies are close to $1 \%$ of the observed ones, the latter are used in the computations to obtain accurate positions of the resonances.
All levels of total angular momentum symmetries 1/ $2 \leq J \leq 11 / 2$ are considered. With largest partial wave of the outer electron $l=7$, these correspond to $0 \leq L \leq 7$ in doublet and quartet spin symmetries. The $R$-matrix basis set is represented by 30 continuum functions. It is necessary to represent the wave function expansion in the inner region of the $R$-matrix boundary with a relatively large number of terms in order to avoid numerical problems.

$$
\text { 3.2. } e+\mathrm{Fe} \mathrm{XXvI} \rightarrow \mathrm{Fe} \mathrm{XXv}
$$

The wave function expansion of $\mathrm{Fe} \mathrm{XXV}$ is represented by nine fine-structure levels (Table 1) of hydrogenic Fe XXVI from 1 s to $3 d$.

The highest partial wave considered is $l=9$ giving $S L \pi$ symmetries consisting of $0 \leq L \leq 9$ of singlet and triplet 

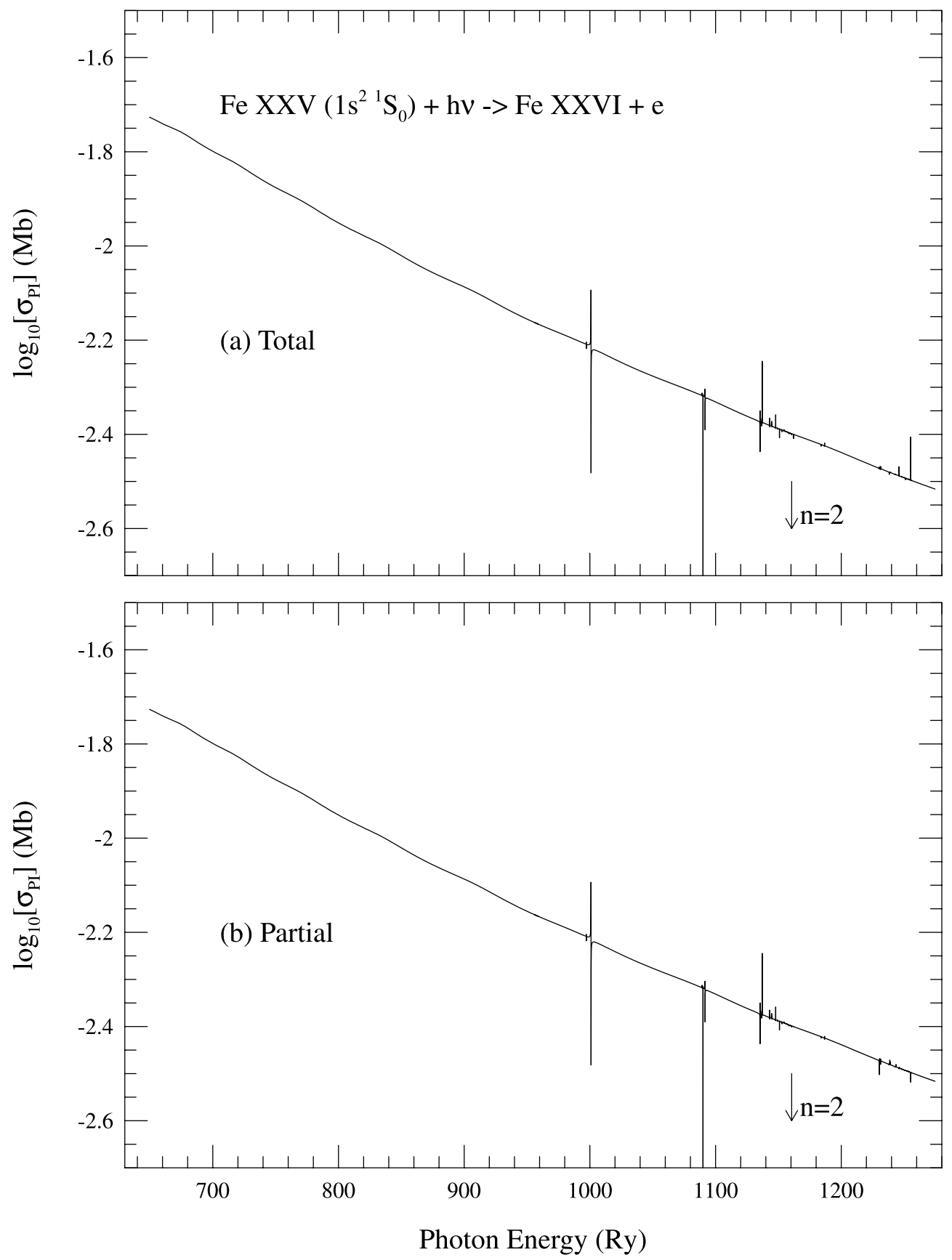

FIG. 2.-Photoionization of the ground state $1 s^{2}\left({ }^{1} S_{0}\right)$ of Fe XXv: (a) partial cross section into the ground level $1 s\left({ }^{2} S_{1 / 2}\right)$ of Fe XXVI ; $(b)$ total cross section.

spin symmetries, for even and odd parities. All levels of Fe XXV with total angular momentum symmetry $0 \leq J \leq 7$ for even and 8 for odd parity are included. The $R$-matrix basis set consists of 20 terms.

\section{RESULTS AND DISCUSSION}

Results for photoionization and recombination are presented below, followed by a discussion of the physical features and effects.

\subsection{Photoionization}

Total and partial ground-state cross sections (into the ground and excited levels of the residual ion, and into the ground level only, respectively) are needed for various astrophysical models, such as in determination of ionization fractions in photoionization equilibrium and non-LTE spectral models. Figures 1 and 2 present the ground-state photoionization cross section for Fe XXIV $\left(1 s^{2} 2 s^{2} S_{1 / 2}\right)$ and Fe XXV $\left(1 s^{2}{ }^{1} S_{0}\right)$. Figures $1 a$ and $2 a$ show the partial cross section into the ground level of the residual ion, and Figures $1 b$ and $2 b$ show the total cross section (sum of ionization into various target levels) of the residual ion. For Fe XXIV and Fe Xxv, the first excited target $n=2$ threshold(s) lie at high energies, and the cross sections show a monotonic decrease over a relatively large energy range. The total and the partial cross sections are identical below the first excited level of the residual ion, as shown in the figures. The resonances at high energies belong to Rydberg series of $n=2,3$ levels. Owing to the high ion charge $z$, the resonance 

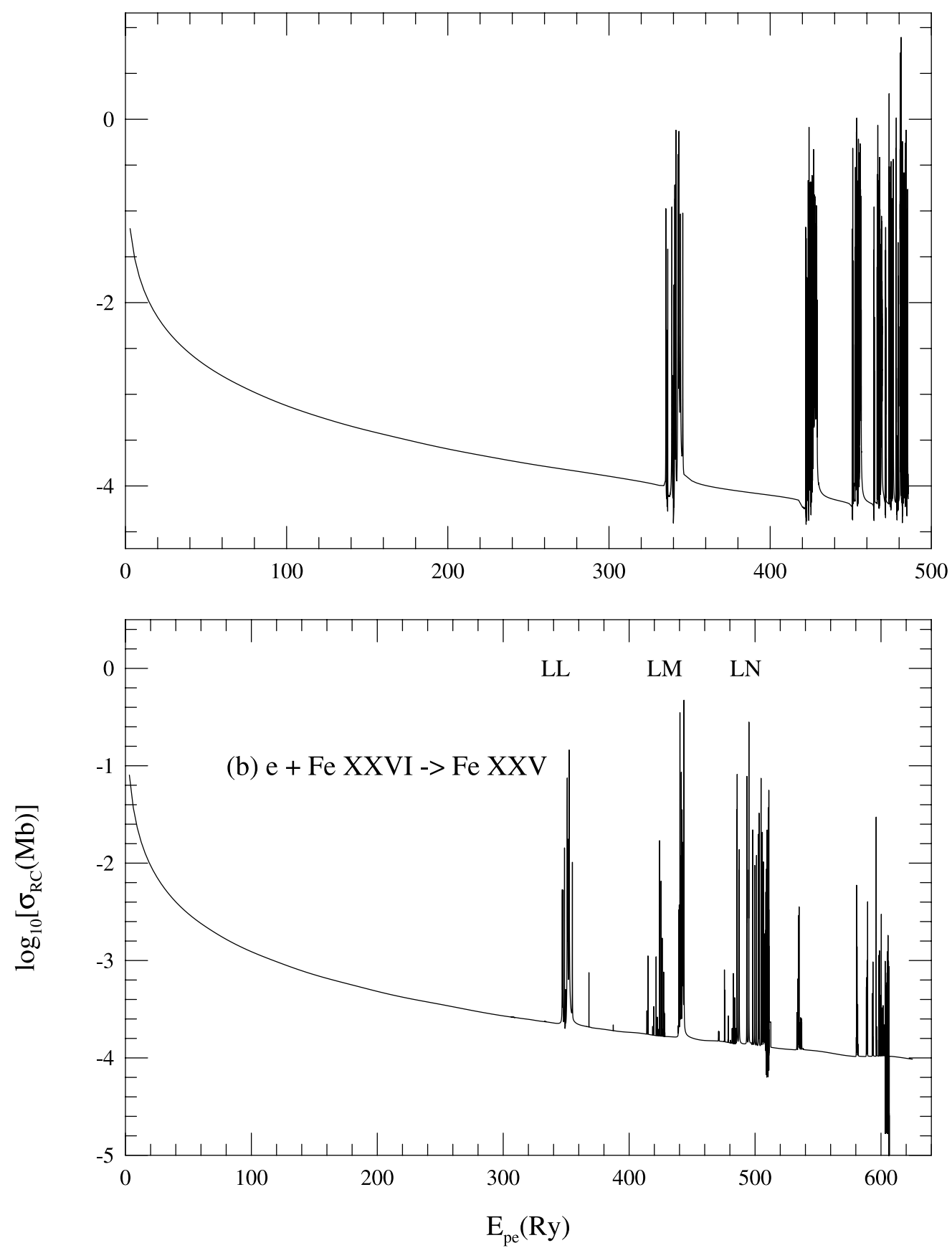

FIG. 3.-Total unified $\left(e+\right.$ ion) photorecombination cross sections, $\sigma_{\mathrm{RC}}$, of $(a)$ Fe XxIV and $(b) \mathrm{Fe}$ XXv. Note that the $\sigma_{\mathrm{RC}}$ exhibit considerably more resonance structures than the corresponding ground level $\sigma_{\mathrm{PI}}$ in Figs. 1 and 2, since the former are summed over the ground and many excited recombined levels.

complexes-groups of levels with the same principal quantum number(s) - are clearly separated, approximately as $z^{2}$ (discussed in the next section).

The total cross sections Figure $1 b$ show the K-shell ionization jump at the $n=2$ target levels, i.e., inner-shell photoionization:

$$
h v+\mathrm{Fe} \operatorname{xxIv}\left(1 s^{2} 2 s\right) \rightarrow e+\mathrm{Fe} \operatorname{xxv}(1 s 2 s, 1 s 2 p) .
$$

Figure $1 c$ displays an expanded view of the resonance structures and the inner-shell ionization energy regions. In X-ray photoionization models, the inner-shell edges play an important role in the overall ionization rates.

In order to delineate the resonances for recombination calculations fully, it is necessary to compute the partial cross sections at a very large number of points, typically tens of thousands of energies. However, for ionization balance calculations, it may not be necessary to compute the total photoionization cross sections at an equally fine mesh since the photoionization rate usually depends on the convolution over a slowly varying radiation field with frequency.

\section{RECOMBINATION CROSS SECTIONS AND RATE COEFFICIENTS}

Figures $3 a$ and $3 b$ present the total recombination cross sections $\sigma_{\mathrm{RC}}$, summed over all contributing fine-structure 


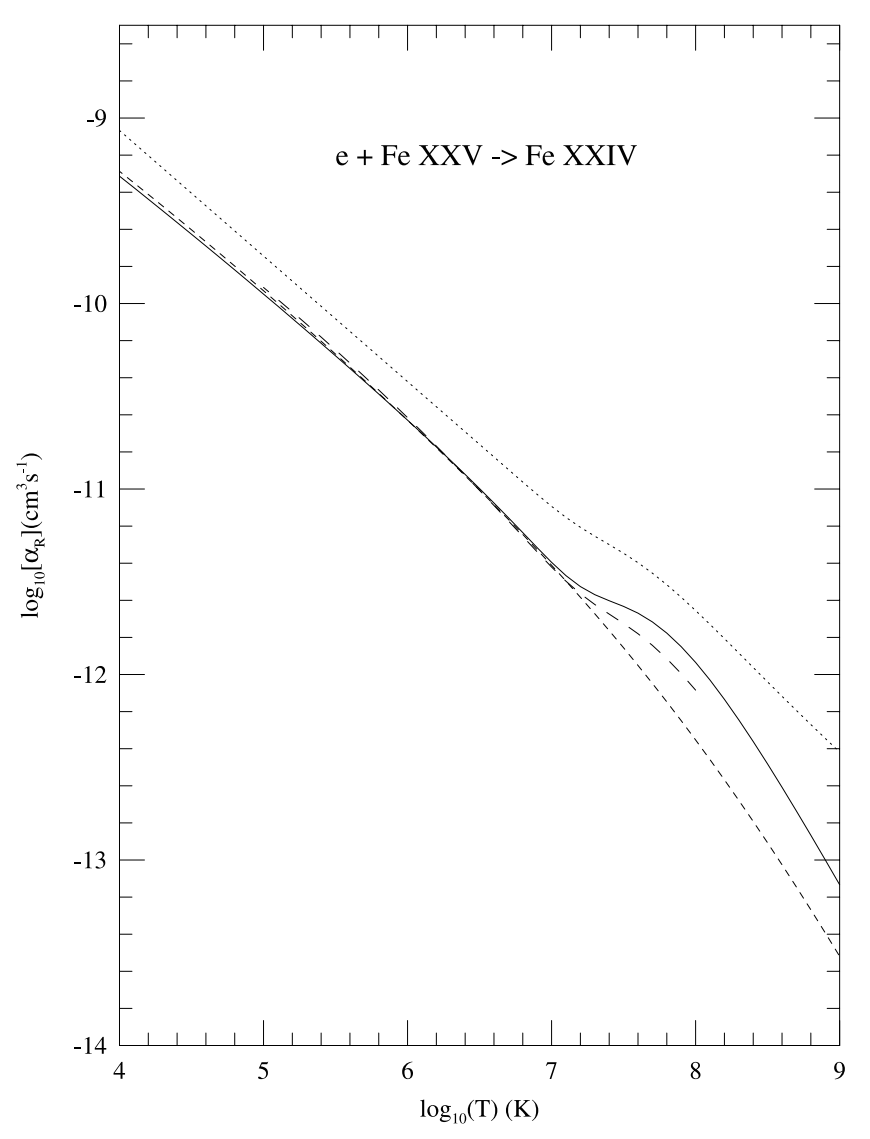

FIG. 4.-Total unified rate coefficients for Fe XxIv: BPRM with fine structure (solid curve); sum of (RR + DR) rates : from Arnaud \& Raymond (1992) (long-dashed curve); from Woods et al. (1981) (dotted curve); RR rates from Verner \& Ferland (1996) (short-dashed curve).

levels up to $n=10$, for Fe XXIV and Fe XXv. The resonance complexes for Fe XXIV are marked as KLL, KLM, KLN, etc., and those for Fe XXV as LL, LM, LN, etc. These are the complexes of dielectronic satellite lines observed in tokamaks, electron-beam-ion-traps (EBIT), ion storage rings, and astrophysical sources. In particular, the KLL complex has been well studied theoretically (e.g., Gabriel 1972; BelyDubau et al. 1982) and experimentally (e.g., Beirsdorfer et al. 1992). In an earlier work on radiation damping of resonances (Pradhan \& Zhang 1997), the theoretical intensities of the individual KLL dielectronic satellite lines were calculated and compared with several other theoretical calculations and the EBIT experiment (Beirsdorfer et al. 1992). The agreement of the KLL satellite lines with experiment is generally about $10 \%-20 \%$ (Pradhan \& Zhang 1997). Later calculations by Zhang et al. (1999) were extended to the KLM, KLN, KLO, and KLP complexes and compared with other theoretical calculations (Badnell, Gorczyca, \& Price 1998) to investigate the effects of radiation damping on the contribution of these complexes to the total recombination rate coefficients of $\mathrm{Fe}$ xxIV.

The unified total BPRM recombination rate coefficients, $\alpha_{R}(T)$, of $e+\mathrm{Fe} \mathrm{XXV} \rightarrow \mathrm{Fe} \mathrm{xxIV}$ and $e+\mathrm{Fe} \mathrm{XXVI} \rightarrow \mathrm{Fe} \mathrm{XXV}$ averaged over a Maxwellian distribution are presented in Table 2. The features of the total recombination rates (solid curves) are shown in Figure 4 for Fe XxIV and in Figure 5 for $\mathrm{Fe} x \mathrm{xv}$. The general features are similar to other ions, as explained in the first paper in this series (Nahar \& Pradhan

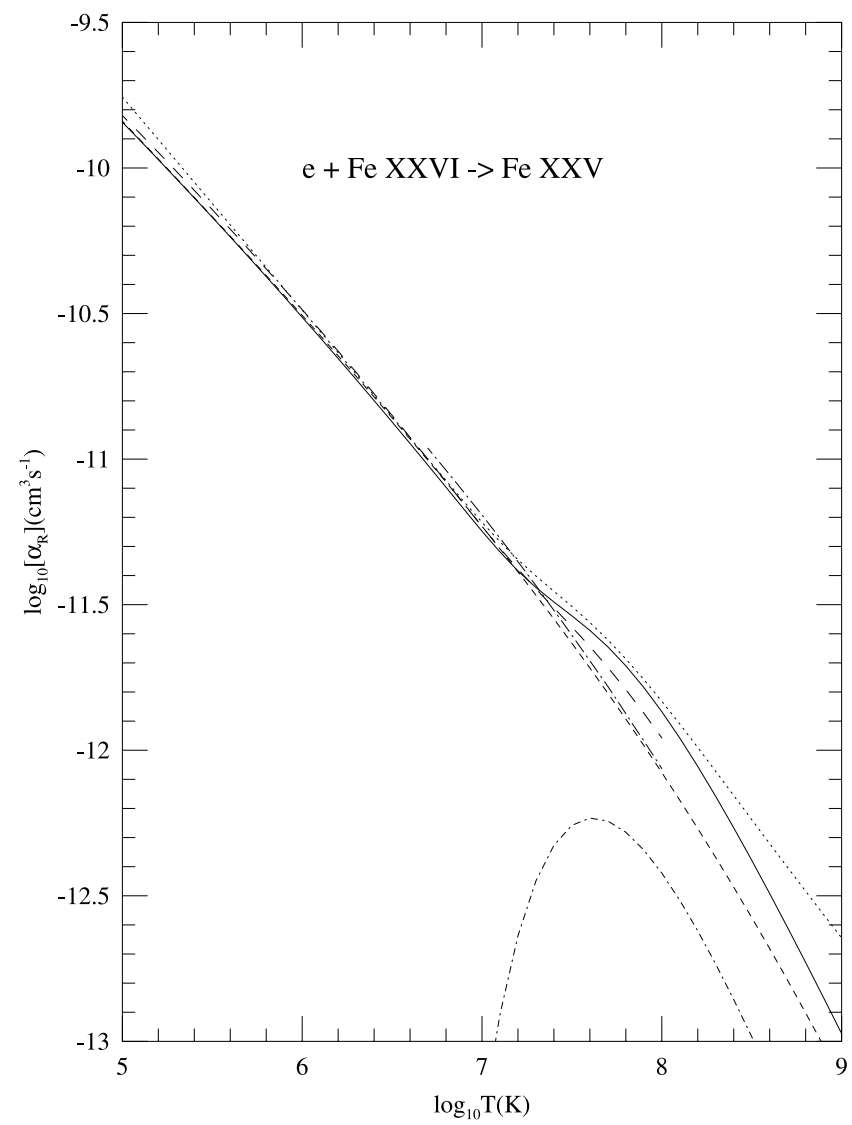

FIG. 5.-Total unified rate coefficients for Fe Xxv: BPRM with fine structure (solid curve); sum of (RR + DR) rates: from Arnaud \& Raymond (1992) (long-dashed curve), from Woods et al. (198)1 (dotted curve), from Bely-Dubau et al. (1982) (dot-long-dashed curve); RR-only rates from Verner \& Ferland (1996) (short-dashed curve); DR-only rates from Romanik (1988) (dot-dashed curve).

1997). As pointed out in our earlier works on unified recombination rates, the total $(e+$ ion) recombination rate generally decreases with temperature, dominated essentially by RR but possibly affected by a low-temperature DR "bump," until the relatively higher energy resonances enter via DR resulting in a large DR bump. In Figures 4 and 5, these high-temperature bumps are at about $\log _{10} T(\mathrm{~K})=$ 7.5 for $\mathrm{Fe}$ xxIV and $\log _{10} T(\mathrm{~K})=7.7$ for $\mathrm{Fe}$ xxv, where the total rate rises owing to dominance of DR over RR. The total recombination rate coefficients for the hydrogenic Fe XXVI are also given in Table 2 for completeness.

Figure 4 compares the present total unified BPRM recombination rate coefficients (solid curve) for $e+\mathrm{Fe}$ $\mathrm{XXV} \rightarrow \mathrm{Fe}$ XXIV with several other available sets of data. However, since previous works treat RR and DR as independent processes and obtain those rates individually, we compare the present unified rates with the sum of the two ( RR + DR) rates from earlier works (with the exception of cases where only one set of data is available). The dotted curve is the sum of the RR and DR rates fitted by Woods, Shull, \& Sarazin (1981), and the long-dashed curves are similar fits by Arnaud \& Raymond (1992); original references to the RR and DR data are given in these references. The present rates and those by Arnaud \& Raymond (1992) agree quite well with each other except at very high temperatures where DR dominates. The rates by Arnaud \& 


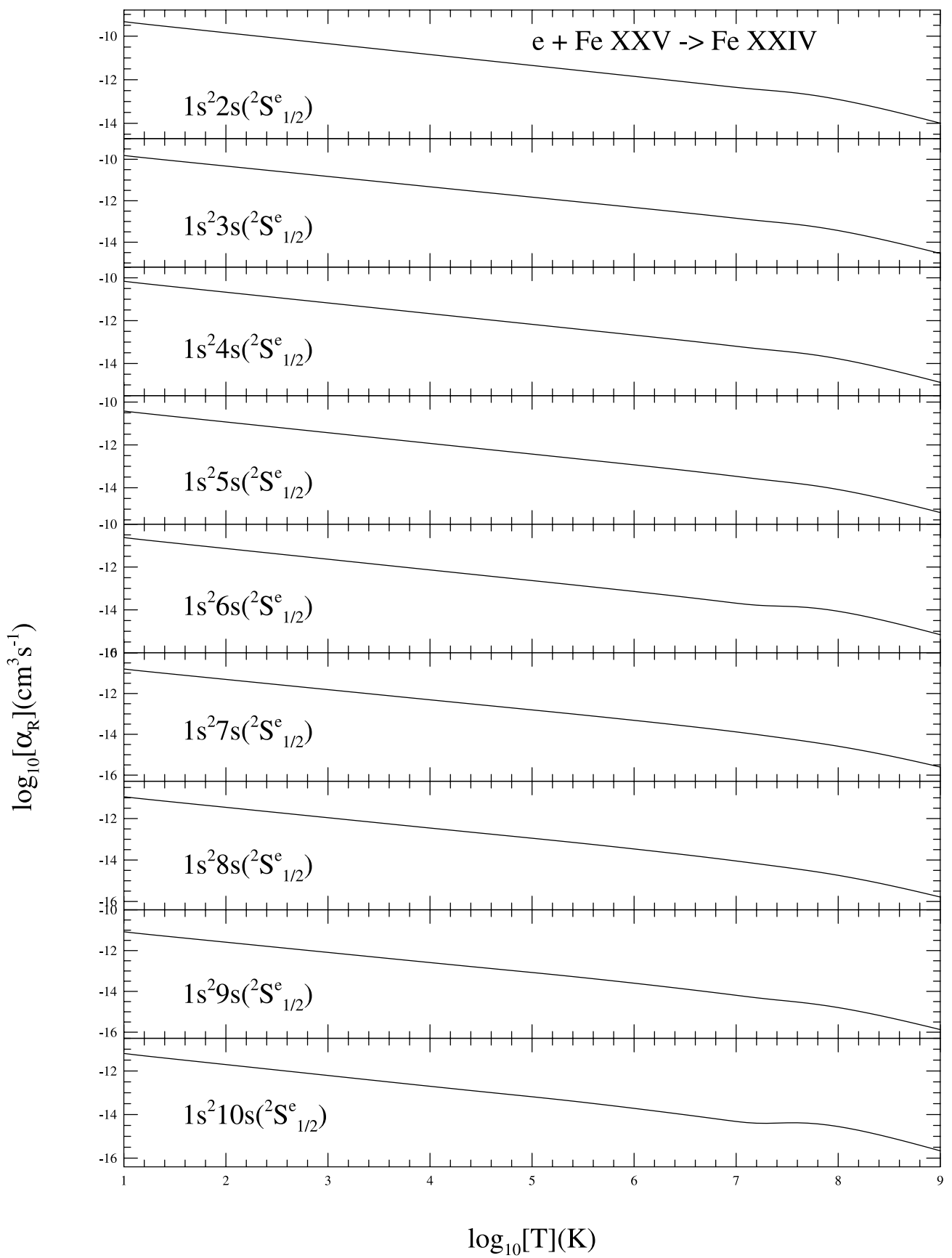

FIG. 6.-Level-specific recombination rate coefficients for Fe XxIv into the ground and excited levels of the $1 s^{2} n s\left({ }^{2} S_{1 / 2}^{e}\right)$ Rydberg series, $n \leq 10$

Raymond show a lower DR peak than the present one. The rates by Woods et al. (1981) are much higher at all temperatures than the present rates or those by Arnaud \& Raymond, who adopted the DR rates computed by Karim \& Bhalla (1988) for individual resonances. Arnaud \& Raymond adopted the rates computed by Karim \& Bhalla (1988), which entailed autoionization and radiative calculations for individual resonances; perhaps the underestimation in their total rate stems from incomplete summation. Woods et al. obtained the RR rates using the Reilman \& Manson (1978) subshell photoionization cross sections in the central-field approximation (without $L S$ multiplet structure), and DR rates from the Burgess (1965) formula. While the present unified rates include both the nonresonant (RR) and the resonant (DR) recombination, previous calculations employ different approximations for these two processes from different sources. Therefore, it is not possible to ascertain precisely the causes of these large discrepancies. The short-dashed curves are the RR-only rates by Verner \& Ferland (1996) that agree well with present ones in the region $\left(T<10^{7} \mathrm{~K}\right)$, where DR is small. It may be noted that the partial rates given in Zhang et al. (1999) were obtained only for the resonant (i.e., DR) recombination cross sections; contributions from the low-energy background cross sections were not included.

Total $\alpha_{R}(T)$ for $e+\mathrm{Fe}$ XXIV $\rightarrow \mathrm{Fe}$ XXV are compared with others in Figure 5. The unified total recombination rates are compared with the $(\mathrm{RR}+\mathrm{DR})$ rates from Woods et al. (1981; dotted curve), Arnaud \& Raymond (1992; longdashed curve), and Bely-Dubau et al. (1982; dot-long-dashed 


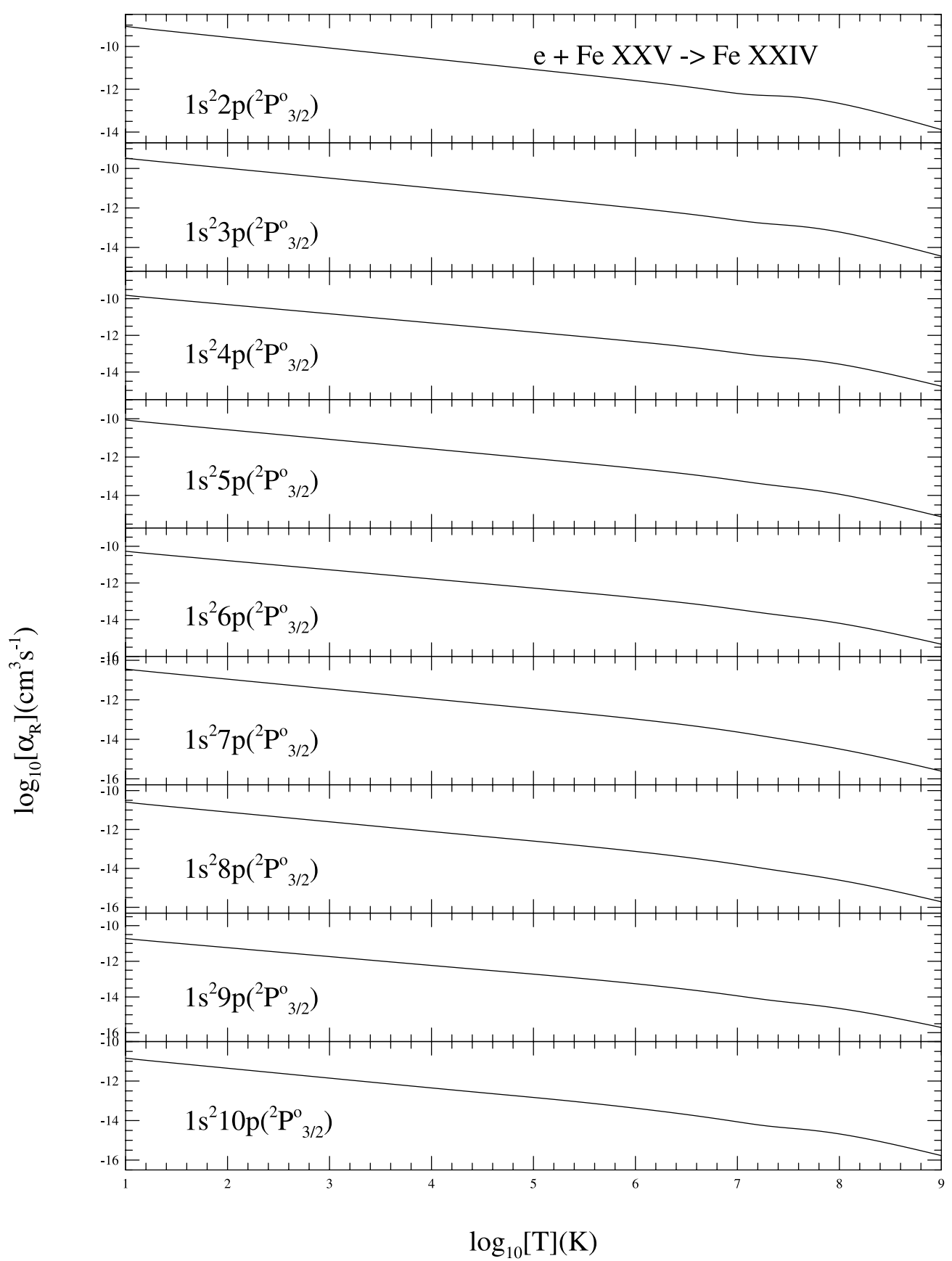

FIG. 7.-Level-specific recombination rate coefficients for Fe XXIV into the excited levels of the $1 s^{2} n p\left({ }^{2} P_{3 / 2}^{o}\right)$ Rydberg series, $n \leq 10$

curve). The unified rates agree well with all except at high temperatures where the rates by Woods et al. are higher and those by Arnaud \& Raymond are lower. Comparison is also shown with the DR-only rates by Romanik (1988; shortdash-dotted curve), which is much lower (without the RR contribution). As expected, the RR-only rates by Verner \& Ferland (1996; short-dashed curve) are in reasonable agreement with the present rates up to temperatures about $\log _{10} T=7.3$, with negligible DR contributions.

\subsection{Level-specific Cross Sections and Rate Coefficients}

In Figures 6 and 7, we show the level-specific recombination rate coefficients into the ground and the excited bound levels of Fe XxIV for the $1 s^{2} n s, n p$ Rydberg series up to $n=10$. These are the first such calculations, and levelspecific data have been obtained for all $\ell \leq 9$ and associated $J \pi$ symmetries. The behavior of the level-specific rates mimics that of the total (this is true only for the simple ions under consideration; in general, the level-specific rates show significantly different structure for complex ions, as seen in our previous works on low-ionization stages of iron, $\mathrm{Fe} \mathrm{I}-\mathrm{Fe} \mathrm{v}$, for example). The only distinguishing feature is the slight DR bump. Since the computations are enormously involved, particularly related to the resolution of resonances, the consistency of the individual level-specific rates along the Rydberg series is an indication of numerical precision.

Figure 8 presents level-specific recombination rate coeffi- 
TABLE 2

Total Recombination Rate Coefficients, $\alpha_{R}(T)$, of Fe xxiv, Fe xxv, AND Fe xxvi

\begin{tabular}{|c|c|c|c|c|c|c|c|}
\hline \multirow{2}{*}{$\begin{array}{c}\log _{10} T \\
(\mathrm{~K})\end{array}$} & \multicolumn{3}{|c|}{$\alpha_{R}\left(\mathrm{~cm}^{3} \mathrm{~s}^{-1}\right)$} & \multirow{2}{*}{$\begin{array}{c}\log _{10} T \\
(\mathrm{~K})\end{array}$} & \multicolumn{3}{|c|}{$\alpha\left(\mathrm{cm}^{3} \mathrm{~s}^{-1}\right)$} \\
\hline & Fe XXIV & $\mathrm{Fe} \times x \mathrm{x}$ & Fe XXVI & & Fe XXIV & Fe XXV & Fe XXVI \\
\hline 1.0. & $2.38 \mathrm{E}-08$ & $2.79 \mathrm{E}-08$ & $3.21 \mathrm{E}-08$ & 5.1 . & $9.67 \mathrm{E}-11$ & $1.24 \mathrm{E}-10$ & $1.52 \mathrm{E}-10$ \\
\hline $1.1 \ldots \ldots$ & $2.11 \mathrm{E}-08$ & $2.48 \mathrm{E}-08$ & $2.85 \mathrm{E}-08$ & 5.2. & $8.30 \mathrm{E}-11$ & $1.07 \mathrm{E}-10$ & $1.32 \mathrm{E}-10$ \\
\hline $1.2 \ldots \ldots$ & $1.88 \mathrm{E}-08$ & $2.21 \mathrm{E}-08$ & $2.54 \mathrm{E}-08$ & $5.3 \ldots$ & $7.12 \mathrm{E}-11$ & $9.18 \mathrm{E}-11$ & $1.14 \mathrm{E}-10$ \\
\hline $1.3 .$. & $1.67 \mathrm{E}-08$ & $1.96 \mathrm{E}-08$ & $2.25 \mathrm{E}-08$ & $5.4 \ldots$ & $6.10 \mathrm{E}-11$ & $7.89 \mathrm{E}-11$ & $9.85 \mathrm{E}-11$ \\
\hline $1.4 \ldots$ & $1.48 \mathrm{E}-08$ & $1.74 \mathrm{E}-08$ & $2.00 \mathrm{E}-08$ & $5.5 \ldots$ & $5.22 \mathrm{E}-11$ & $6.77 \mathrm{E}-11$ & $8.51 \mathrm{E}-11$ \\
\hline $1.5 \ldots \ldots$ & $1.31 \mathrm{E}-08$ & $1.55 \mathrm{E}-08$ & $1.78 \mathrm{E}-08$ & $5.6 \ldots$ & $4.47 \mathrm{E}-11$ & $5.80 \mathrm{E}-11$ & $7.34 \mathrm{E}-11$ \\
\hline $1.6 \ldots \ldots$ & $1.16 \mathrm{E}-08$ & $1.37 \mathrm{E}-08$ & $1.58 \mathrm{E}-08$ & $5.7 \ldots \ldots$ & $3.81 \mathrm{E}-11$ & $4.96 \mathrm{E}-11$ & $6.33 \mathrm{E}-11$ \\
\hline $1.7 \ldots \ldots$ & $1.03 \mathrm{E}-08$ & $1.22 \mathrm{E}-08$ & $1.40 \mathrm{E}-08$ & $5.8 \ldots \ldots$ & $3.25 \mathrm{E}-11$ & $4.23 \mathrm{E}-11$ & $5.45 \mathrm{E}-11$ \\
\hline $1.8 \ldots \ldots$ & $9.13 \mathrm{E}-09$ & $1.08 \mathrm{E}-08$ & $1.24 \mathrm{E}-08$ & $5.9 \ldots \ldots$ & $2.77 \mathrm{E}-11$ & $3.61 \mathrm{E}-11$ & $4.69 E-11$ \\
\hline $1.9 \ldots \ldots$ & $8.06 \mathrm{E}-09$ & $9.53 \mathrm{E}-09$ & $1.10 \mathrm{E}-08$ & $6.0 \ldots$ & $2.35 \mathrm{E}-11$ & $3.07 \mathrm{E}-11$ & $4.02 \mathrm{E}-11$ \\
\hline $2.0 \ldots \ldots$ & $7.12 \mathrm{E}-09$ & $8.42 \mathrm{E}-09$ & $9.71 \mathrm{E}-09$ & $6.1 \ldots \ldots$ & $1.99 \mathrm{E}-11$ & $2.61 \mathrm{E}-11$ & $3.46 \mathrm{E}-11$ \\
\hline $2.1 \ldots \ldots$ & $6.28 \mathrm{E}-09$ & $7.44 \mathrm{E}-09$ & $8.58 \mathrm{E}-09$ & 6.2. & $1.69 \mathrm{E}-11$ & $2.22 \mathrm{E}-11$ & $2.96 \mathrm{E}-11$ \\
\hline $2.2 .$. & $5.53 \mathrm{E}-09$ & $6.56 \mathrm{E}-09$ & $7.58 \mathrm{E}-09$ & $6.3 \ldots \ldots$ & $1.42 \mathrm{E}-11$ & $1.88 \mathrm{E}-11$ & $2.53 \mathrm{E}-11$ \\
\hline $2.3 \ldots \ldots$ & $4.87 \mathrm{E}-09$ & $5.78 \mathrm{E}-09$ & $6.69 \mathrm{E}-09$ & $6.4 \ldots \ldots$ & $1.20 \mathrm{E}-11$ & $1.59 \mathrm{E}-11$ & $2.17 \mathrm{E}-11$ \\
\hline $2.4 \ldots \ldots$ & $4.29 \mathrm{E}-09$ & $5.09 \mathrm{E}-09$ & $5.90 \mathrm{E}-09$ & $6.5 \ldots \ldots$ & $1.00 \mathrm{E}-11$ & $1.34 \mathrm{E}-11$ & $1.85 \mathrm{E}-11$ \\
\hline $2.5 \ldots \ldots$ & $3.76 \mathrm{E}-09$ & $4.48 \mathrm{E}-09$ & $5.20 \mathrm{E}-09$ & $6.6 \ldots$ & $8.40 \mathrm{E}-12$ & $1.13 \mathrm{E}-11$ & $1.58 \mathrm{E}-11$ \\
\hline $2.6 \ldots \ldots$ & $3.30 \mathrm{E}-09$ & $3.94 \mathrm{E}-09$ & $4.57 \mathrm{E}-09$ & $6.7 \ldots \ldots$ & $7.00 \mathrm{E}-12$ & $9.52 \mathrm{E}-12$ & $1.34 \mathrm{E}-11$ \\
\hline $2.7 .$. & $2.90 \mathrm{E}-09$ & $3.46 \mathrm{E}-09$ & $4.02 \mathrm{E}-09$ & $6.8 \ldots$ & $5.82 \mathrm{E}-12$ & $8.01 \mathrm{E}-12$ & $1.14 \mathrm{E}-11$ \\
\hline $2.8 \ldots \ldots$ & $2.54 \mathrm{E}-09$ & $3.04 \mathrm{E}-09$ & $3.53 \mathrm{E}-09$ & $6.9 \ldots \ldots$ & $4.83 \mathrm{E}-12$ & $6.72 \mathrm{E}-12$ & $9.64 \mathrm{E}-12$ \\
\hline $2.9 \ldots \ldots$ & $2.22 \mathrm{E}-09$ & $2.67 \mathrm{E}-09$ & $3.10 \mathrm{E}-09$ & $7.0 \ldots \ldots$ & $4.02 \mathrm{E}-12$ & $5.65 E-12$ & $8.14 \mathrm{E}-12$ \\
\hline $3.0 \ldots \ldots$ & $1.94 \mathrm{E}-09$ & $2.33 \mathrm{E}-09$ & $2.72 \mathrm{E}-09$ & $7.1 \ldots$ & $3.41 \mathrm{E}-12$ & $4.80 \mathrm{E}-12$ & $6.88 E-12$ \\
\hline $3.1 \ldots \ldots$ & $1.70 \mathrm{E}-09$ & $2.04 \mathrm{E}-09$ & $2.39 \mathrm{E}-09$ & $7.2 \ldots$ & $2.98 \mathrm{E}-12$ & $4.13 E-12$ & $5.78 \mathrm{E}-12$ \\
\hline $3.2 \ldots \ldots$ & $1.48 \mathrm{E}-09$ & $1.79 \mathrm{E}-09$ & $2.09 \mathrm{E}-09$ & $7.3 \ldots \ldots$ & $2.69 \mathrm{E}-12$ & $3.62 \mathrm{E}-12$ & $4.85 \mathrm{E}-12$ \\
\hline $3.3 \ldots \ldots$ & $1.29 \mathrm{E}-09$ & $1.56 \mathrm{E}-09$ & $1.83 \mathrm{E}-09$ & $7.4 \ldots$ & $2.50 \mathrm{E}-12$ & $3.23 \mathrm{E}-12$ & $4.06 \mathrm{E}-12$ \\
\hline $3.4 \ldots \ldots$ & $1.13 \mathrm{E}-09$ & $1.36 \mathrm{E}-09$ & $1.60 \mathrm{E}-09$ & $7.5 \ldots \ldots$ & $2.33 \mathrm{E}-12$ & $2.89 \mathrm{E}-12$ & $3.38 \mathrm{E}-12$ \\
\hline $3.5 \ldots \ldots$ & $9.81 \mathrm{E}-10$ & $1.19 \mathrm{E}-09$ & $1.40 \mathrm{E}-09$ & $7.6 \ldots$ & $2.14 \mathrm{E}-12$ & $2.58 \mathrm{E}-12$ & $2.81 \mathrm{E}-12$ \\
\hline $3.6 \ldots \ldots$ & $8.54 \mathrm{E}-10$ & $1.04 \mathrm{E}-09$ & $1.23 \mathrm{E}-09$ & $7.7 .$. & $1.92 \mathrm{E}-12$ & $2.27 \mathrm{E}-12$ & $2.32 \mathrm{E}-12$ \\
\hline $3.7 \ldots \ldots$ & $7.42 \mathrm{E}-10$ & $9.07 \mathrm{E}-10$ & $1.07 \mathrm{E}-09$ & $7.8 \ldots$ & $1.67 \mathrm{E}-12$ & $1.95 \mathrm{E}-12$ & $1.92 \mathrm{E}-12$ \\
\hline $3.8 \ldots \ldots$ & $6.45 \mathrm{E}-10$ & $7.90 \mathrm{E}-10$ & $9.35 \mathrm{E}-10$ & $7.9 \ldots \ldots$ & $1.41 \mathrm{E}-12$ & $1.64 \mathrm{E}-12$ & $1.57 \mathrm{E}-12$ \\
\hline $3.9 \ldots \ldots$ & $5.60 \mathrm{E}-10$ & $6.89 \mathrm{E}-10$ & $8.16 \mathrm{E}-10$ & $8.0 \ldots$ & $1.16 \mathrm{E}-12$ & $1.36 \mathrm{E}-12$ & $1.28 \mathrm{E}-12$ \\
\hline $4.0 \ldots \ldots$ & $4.86 \mathrm{E}-10$ & $5.99 \mathrm{E}-10$ & $7.11 \mathrm{E}-10$ & $8.1 \ldots \ldots$ & $9.33 \mathrm{E}-13$ & $1.10 \mathrm{E}-12$ & $1.04 \mathrm{E}-12$ \\
\hline $4.1 \ldots \ldots$ & $4.22 \mathrm{E}-10$ & $5.22 \mathrm{E}-10$ & $6.21 \mathrm{E}-10$ & 8.2. & $7.35 \mathrm{E}-13$ & $8.80 \mathrm{E}-13$ & $8.40 \mathrm{E}-13$ \\
\hline $4.2 \ldots \ldots$ & $3.65 \mathrm{E}-10$ & $4.53 \mathrm{E}-10$ & $5.41 \mathrm{E}-10$ & 8.3. & $5.69 \mathrm{E}-13$ & $6.94 \mathrm{E}-13$ & $6.73 \mathrm{E}-13$ \\
\hline $4.3 \ldots \ldots$ & $3.16 \mathrm{E}-10$ & $3.93 \mathrm{E}-10$ & $4.70 \mathrm{E}-10$ & $8.4 \ldots \ldots$ & $4.35 \mathrm{E}-13$ & $5.41 \mathrm{E}-13$ & $5.37 \mathrm{E}-13$ \\
\hline $4.4 \ldots \ldots$ & $2.73 \mathrm{E}-10$ & $3.42 \mathrm{E}-10$ & $4.10 \mathrm{E}-10$ & $8.5 \ldots \ldots$ & $3.29 \mathrm{E}-13$ & $4.19 E-13$ & $4.26 \mathrm{E}-13$ \\
\hline $4.5 \ldots \ldots$ & $2.36 \mathrm{E}-10$ & $2.96 \mathrm{E}-10$ & $3.56 \mathrm{E}-10$ & $8.6 \ldots \ldots$ & $2.47 \mathrm{E}-13$ & $3.22 \mathrm{E}-13$ & $3.36 \mathrm{E}-13$ \\
\hline $4.6 \ldots \ldots$ & $2.04 \mathrm{E}-10$ & $2.57 \mathrm{E}-10$ & $3.10 \mathrm{E}-10$ & $8.7 \ldots \ldots$ & $1.84 \mathrm{E}-13$ & $2.46 \mathrm{E}-13$ & $2.63 \mathrm{E}-13$ \\
\hline $4.7 \ldots \ldots$ & $1.76 \mathrm{E}-10$ & $2.23 \mathrm{E}-10$ & $2.69 \mathrm{E}-10$ & $8.8 \ldots \ldots$ & $1.36 \mathrm{E}-13$ & $1.87 \mathrm{E}-13$ & $2.05 \mathrm{E}-13$ \\
\hline $4.8 \ldots \ldots$ & $1.52 \mathrm{E}-10$ & $1.92 \mathrm{E}-10$ & $2.34 \mathrm{E}-10$ & $8.9 \ldots \ldots$ & $1.00 \mathrm{E}-13$ & $1.41 \mathrm{E}-13$ & $1.59 \mathrm{E}-13$ \\
\hline $4.9 \ldots \ldots$ & $1.31 \mathrm{E}-10$ & $1.67 \mathrm{E}-10$ & $2.03 \mathrm{E}-10$ & $9.0 \ldots \ldots$ & $7.36 \mathrm{E}-14$ & $1.06 \mathrm{E}-13$ & $1.22 \mathrm{E}-13$ \\
\hline $5.0 \ldots \ldots$ & $1.12 \mathrm{E}-10$ & $1.44 \mathrm{E}-10$ & $1.76 \mathrm{E}-10$ & & & & \\
\hline
\end{tabular}

cients of $1 \operatorname{sns}\left({ }^{3} S\right)$ Rydberg series of Fe Xxv levels up to $n=10$. The features are similar to those of Fe XXIV. Although resolution of resonances in each cross section is very cumbersome, the sum of the level-specific rate coefficients, together with the DR contribution, agrees within a few percent with the total recombination rate coefficient obtained from the total collision strengths, thus providing a numerical and self-consistency check.

\section{2. $X$-Ray Transitions $w, x, y, z$ in Fe $\mathrm{xxv}$ : Photoionization and Recombination}

The first detailed BPRM calculations for level-specific photoionization from, and recombination into, the $n=2$ levels of Fe XXV are presented. Figures 9 and 10 respectively show the level-specific photoionization cross sections and recombination rate coefficients, for the ground and the excited $n=2$ levels that are of considerable importance in
$\mathrm{X}$-ray spectroscopy as they are responsible for the formation of the $w, x, y, z$ lines from the four transitions $1 s^{2}$ $\left({ }^{1} S_{0}\right) \leftarrow 1 s 2 p\left({ }^{1} P_{1}^{o}\right), 1 s 2 p\left({ }^{3} P_{2}^{o}\right), 1 s 2 p\left({ }^{3} P_{1}^{o}\right), 1 s 2 s\left({ }^{3} S_{1}\right)$, respectively. The present work is particularly relevant to the formation of these X-ray lines since recombination cascades from excited levels play an important role in determining the intensity ratios in coronal equilibrium and nonequilibrium plasmas (Pradhan 1985). The cross sections in Figure 9 show the K-shell ionization jump at the $n=2$ target levels, i.e., from photoionization as

$$
h v+\mathrm{Fe} \operatorname{xxv}(1 s 2 s, 1 s 2 p) \rightarrow e+\mathrm{Fe} \operatorname{xxvI}(2 s, 2 p) .
$$

The level-specific rates in Figure 10 are in reasonable agreement with those obtained by Mewe \& Schrijver (1978, hereafter MS) that have been widely employed in the calculation of X-ray spectra of He-like ions (e.g., Pradhan 1982). This is 


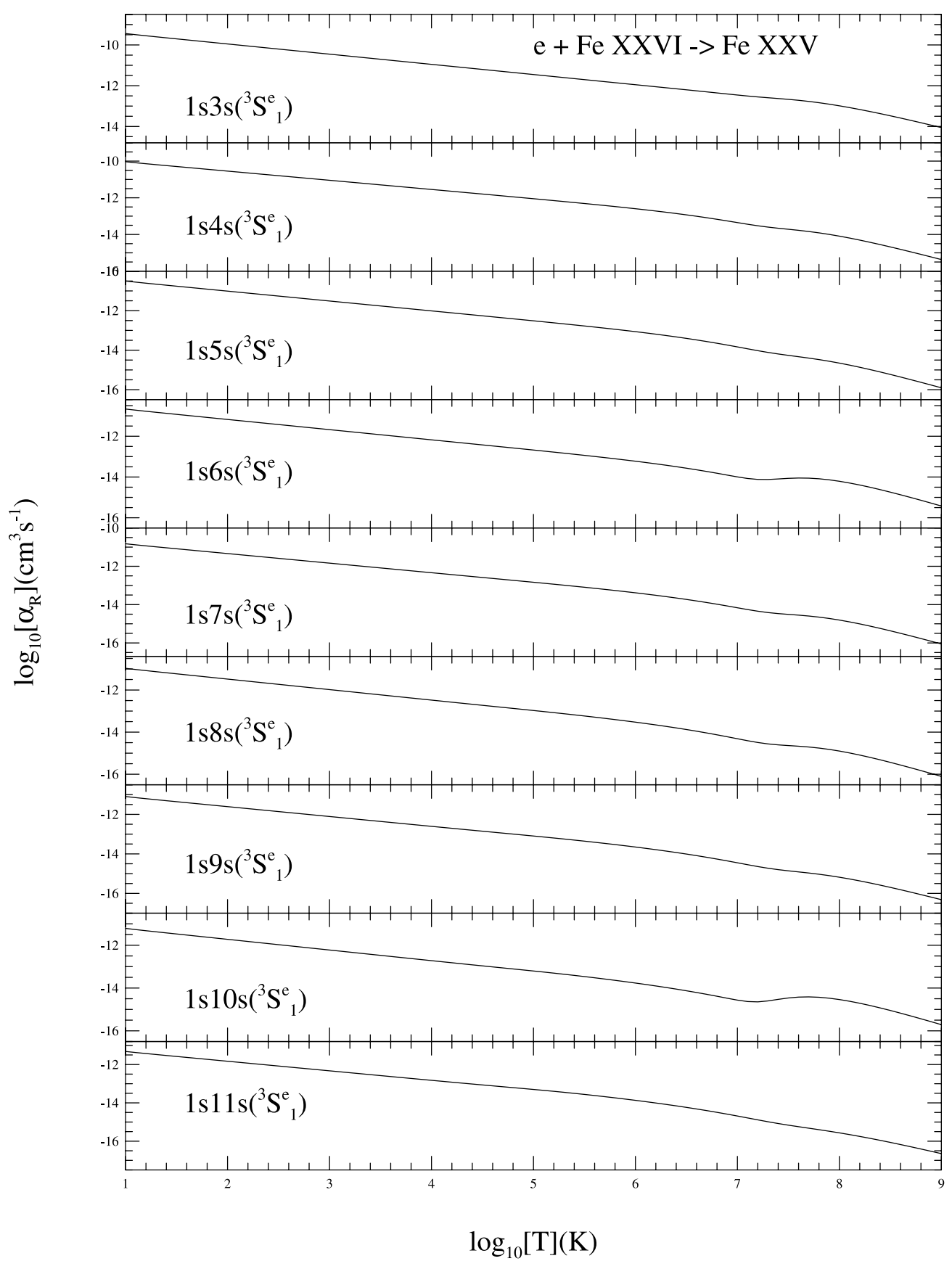

FIG. 8. - Level-specific recombination rate coefficients for Fe xxv into the excited levels of the $1 s n s\left({ }^{3} S_{1}^{e}\right)$ Rydberg series, $n \leq 11$

quite unlike the case for He-like $\mathrm{C} v$, where the unified level-specific rates differed considerably with those of MS (Nahar et al. 2000). We compare with the direct (RR + DR) rates, separately calculated by MS using approximate $Z$ scaled RR and DR rates for the individual $n=2$ levels of He-like ions. Their RR rates were from $Z$-scaled recombination rate of He II given by Burgess \& Seaton (1960); the $L S$ coupling data were divided according to the statistical weights of the fine-structure levels. The MS DR rates were obtained using averaged autoionization probabilities for iron calculated with hydrogenic wave functions, together with radiative decay probabilities of the resonant $2 s 2 p$, $2 p^{2},(2 p 3 s, 2 p 3 p, 2 p 3 d)$ levels, decaying to the final $n=2$ levels. Although the present work includes DR contributions from all resonances up to $2 p n \ell ; n \leq 10, \ell \leq$ $n-1$ (Figs. $3 a$ and $3 b$ ), the final values appear to agree well. The most plausible explanation for the good agreement with MS is that their rates were optimized especially for $\mathrm{Fe} \mathrm{Xxv}$.

Using the present level-specific data, recombinationcascade matrices may now be constructed for Fe XXIV and $\mathrm{Fe} \mathrm{XXV}$ to obtain effective recombination rates into specific fine-structure levels $n \mathrm{SLJ}$, with $n \leq 10$ and $\ell \leq n-1$ (e.g., Pradhan 1985). The present data are more than sufficient for extrapolation to high- $n, \ell$ necessary to account for all cascade contributions. Also needed are the radiative tran- 


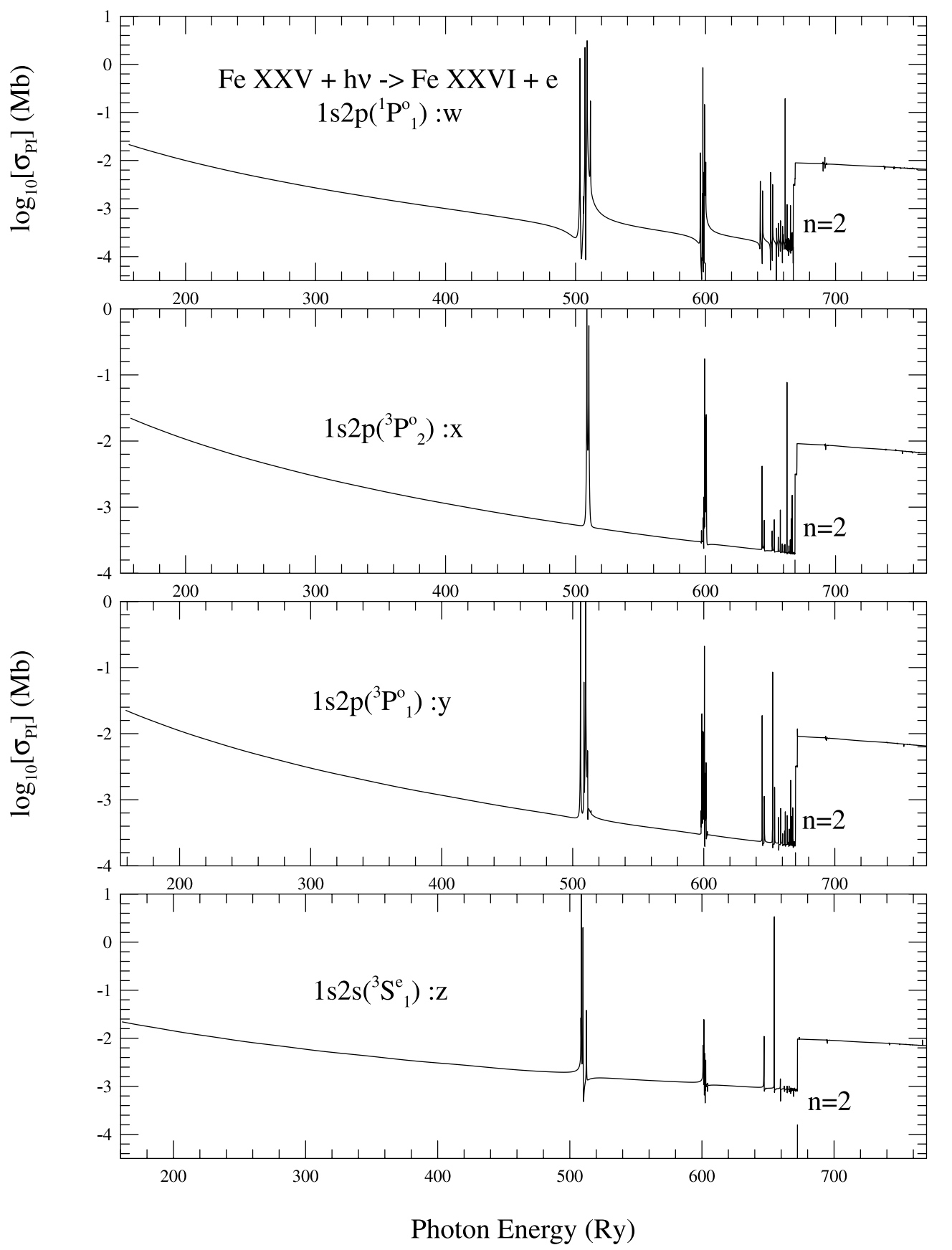

FIG. 9.-Total photoionization cross sections of the excited $n=2$ levels of Fe Xxv. The levels shown are the ones responsible for the prominent X-ray lines $w, x, y$, and $z$.

sition probabilities for all fine-structure levels of $\mathrm{Fe}$ XXIV and Fe XXv up to the $n=10$ levels; those have also been calculated using the BPRM method under the Iron Project (Nahar \& Pradhan 1999).

\section{CONCLUSION}

New relativistic calculations for total and level-specific photoionization and recombination are presented for Fe XXIV and Fe XXV of general interest in X-ray spectroscopy of laboratory and astrophysical sources. The dielectronic satellite rates for the KLL complex of $e+\mathrm{Fe} \mathrm{xxv} \rightarrow$ Fe XXIV, and for several higher complexes, have earlier been shown to be in very good agreement with experiments and other theoretical calculations (Pradhan \& Zhang 1997; Zhang et al. 1999) to about $10 \%-20 \%$; it is therefore expected that the present rates should be definitive, with similar uncertainty.

The unified theoretical formulation and experimental measurements both suggest that the unphysical and imprecise division of the recombination process into "radiative recombination (RR)" and "dielectronic recombination (DR)" may be replaced by "nonresonant" and "resonant" recombination, since these are naturally inseparable.

Further calculations are in progress for oxygen $(\mathrm{O}$ VI and O VII). 


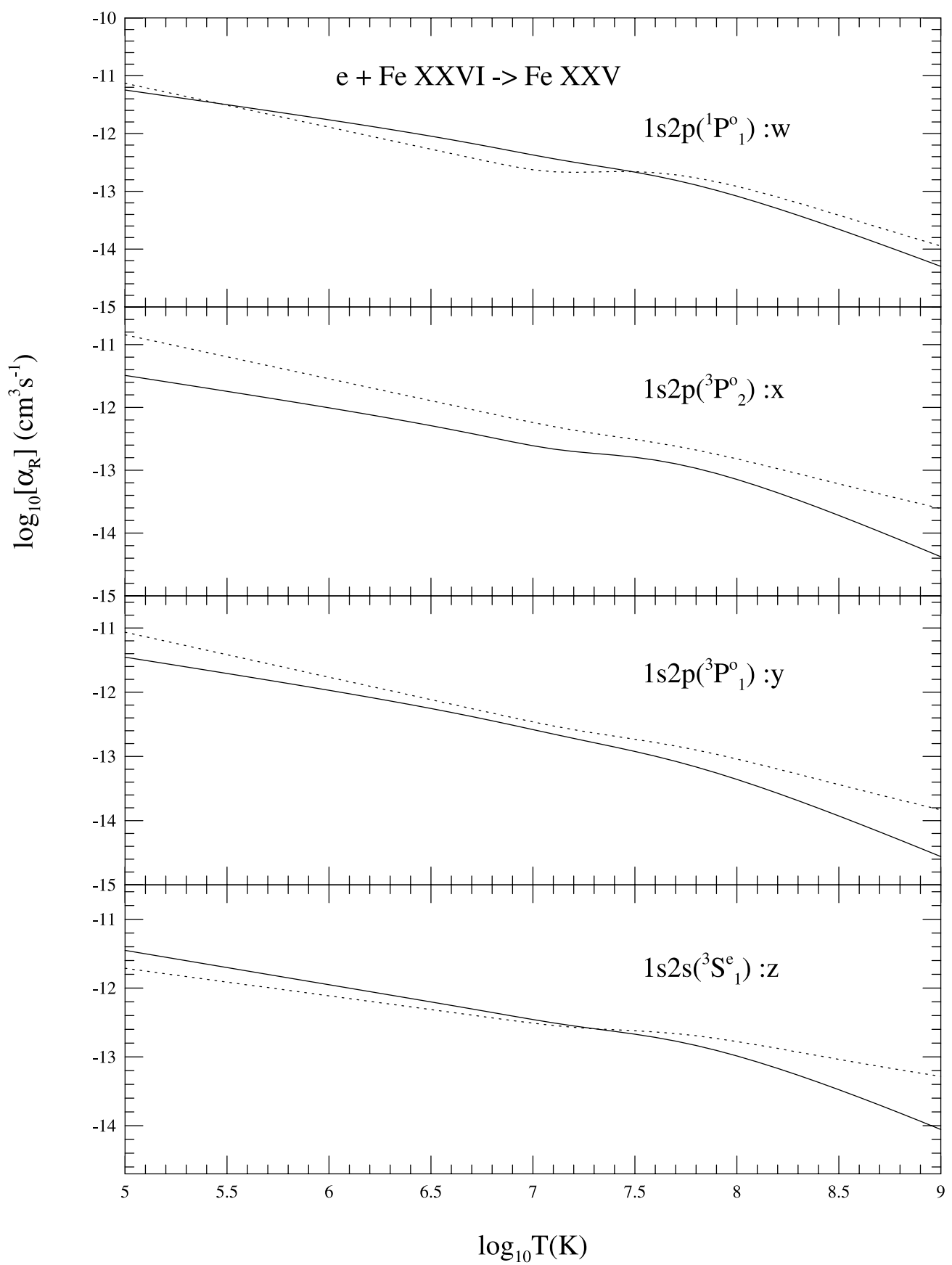

FIG. 10.-Level-specific recombination rate coefficients for Fe Xxv into the excited $n=2$ levels: present (solid curve); Mewe \& Schrijver (1978) (dotted curve). The levels shown are the ones responsible for the prominent X-ray lines $w, x, y$, and $z$.

The available data include the following:

1. Photoionization cross sections for bound finestructure levels of Fe XXIV and Fe XXV up to the $n=10$ complexes - both the total and the partial (into the ground level of the residual ion).

2. Total, unified recombination rates for Fe XXIV and Fe Xxv, and level-specific recombination rate coefficients for levels up to $n=10$.

3. Recombination rate coefficients for H-like Fe XxvI, computed in $L S$ coupling and included for completeness for the computation of ionization fractions toward the highionization end.
All photoionization and recombination data are available electronically from the first author. ${ }^{2}$ The total recombination rate coefficients are also available from the Ohio State Atomic Astrophysics website. ${ }^{3}$

This work was supported partially by grants from NSF (AST-9870089), NASA (NAG5-8423,EL9-1013A). The computational work was carried out on the Cray T94 at the Ohio Supercomputer Center.

\footnotetext{
2 nahar@astronomy.ohio-state.edu.

${ }^{3}$ www.astronomy.ohio - state.edu/ pradhan.
} 


\section{REFERENCES}

Arnaud, M., \& Raymond, J. 1992, ApJ, 398, 394

Badnell, N. R., Gorczyca, T. W., \& Price, A. D. 1998, J. Phys. B, 31, L239

Bautista, M. A., Kallman, T. R., \& Pradhan, A. K., eds. 2000, Atomic Data Needs in X-Ray Astronomy. 2000, /CP-2000-209968, Goddard Space Flight Center, Greenbelt, MD 20771

Beiersdorfer, P., Schneider, M. B., Bitter, M., \& von Goeler, S. 1992, Rev. Sci. Instrum., 63, 5029

Bell, R. H., \& Seaton, M. J. 1985, J. Phys. B, 18, 1589

Bely-Dubau, F., Dubau, J., Faucher, P., \& Gabriel, A. H. 1982, MNRAS, 198, 239

Berrington, K. A., Burke, P. G., Butler, K., Seaton, M. J., Storey, P. J., Taylor, K. T., \& Yan, Y. 1987, J. Phys. B, 20, 6379

Berrington, K. A., Eissner, W., \& Norrington, P. H. 1995, Comput. Phys. Commun., 92, 290

Brickhouse, N., \& Drake, J. 2000, in Atomic Data Needs in X-Ray Astronomy, ed. M.A. Bautista, T. R. Kallman, \& A.K. Pradhan, /CP2000-209968, Goddard Space Flight Center, Greenbelt, MD 20771, 19

Burgess, A. 1965, ApJ, 141, 1588

Burgess, A., \& Seaton, M. J. 1960, MNRAS, 121, 471

Canizares, C. R., et al. 2000, in Atomic Data Needs in X-Ray Astronomy, ed. M. A. Bautista, T. R. Kallman, \& A. K. Pradhan, /CP-2000-209968, Goddard Space Flight Center, Greenbelt, MD 20771, 5

Eissner, W., Jones, M., \& Nussbaumer, H. 1974, Comput. Phys. Commun., 8,270

Gabriel, A. H. 1972, MNRAS, 160, 99
Hummer, D. G., Berrington, K. A., Eissner, W., Pradhan, A. K., Saraph, H. E., \& Tully, J. A. 1993, A\&A, 279, 298

Kaastra, J., \& Mewe, R. 2000, in Atomic Data Needs in X-Ray Astronomy, ed. M. A. Bautista, T. R. Kallman, \& A.K. Pradhan, /CP-2000-209968, Goddard Space Flight Center, Greenbelt, MD 20771, 161

Karim, K. P., \& Bhalla, C. P. 1988, Phys. Rev. A, 37, 2599

Mewe, R., \& Schrijver J. 1978, A\&A, 65, 99

Nahar, S. N. 1996, Phys. Rev. A, 53, 2417

Nahar, S. N., \& Pradhan, A. K. 1994, Phys. Rev. A, 49, 1816 1997, ApJS, 111, 339 1999, A\&AS, 135, 347

Nahar, S. N., Pradhan, A. K., \& Zhang, H. L. 2000, ApJS, 131, 375

Pradhan, A. K. 1982, ApJ, 263, 477

. 1985, ApJ, 284, 824

Pradhan, A. K., \& Shull M. 1981, ApJ, 249, 821

Pradhan, A. K., \& Zhang, H. L. 1997, J. Phys. B, 30, L571

Reilman, R. F., \& Manson, S. T. 1978, Phys. Rev. A, 18, 2124

Romanik, C. J. 1988, ApJ, 330, 1022

Storey, P. J., \& Hummer, D. G. 1992, Comput. Phys. Commun., 66, 129

Opacity Project Team. 1995 and 1996, The Opacity Project 1 \& 2 (London: Institute of Physics)

Verner, D. A., \& Ferland G. 1996, ApJS, 103, 467

Woods, D. T., Shull, J. M., \& Sarazin, C. L. 1981, ApJ, 249, 399

Zhang, H. L., Nahar, S. N., \& Pradhan, A. K. 1999, J. Phys. B, 32, 1459

Note added in proof.-In Figure 5 the DR-only rates from Romanik (1988) refer to Figure 4. 